\title{
Distributions of polychlorinated biphenyls in the Daliao River estuary of Liaodong Bay, Bohai Sea (China)
}

\author{
Bin Men ${ }^{\mathrm{a}, \mathrm{b}}$, Mengchang $\mathrm{He}^{\mathrm{a}, *}$, Li Tan $^{\mathrm{a}}$, Chunye Lin ${ }^{\mathrm{a}}$ \\ a State Key Laboratory of Water Environment Simulation, School of Environment, Beijing Normal University, Beijing 100875, PR China \\ ${ }^{\mathrm{b}}$ State Key Laboratory of Environmental Aquatic Chemistry, Research Centre for Eco-Environmental Sciences, Chinese Academy of Sciences, Beijing 100085, PR China
}

\section{A R T I C L E I N F O}

\section{Keywords:}

PCBs

Polychlorinated biphenyls

Daliao River estuary

Water

SPM

Sediment

\begin{abstract}
A B S T R A C T
The distributions of 41 polychlorinated biphenyls (PCBs) were determined in the aqueous phase, suspended particulate matter (SPM), and sediment of the Daliao River estuary in Liaodong Bay, Bohai Sea (China). The total PCB concentrations ranged from 5.51 to $40.28 \mathrm{ng} \mathrm{L}^{-1}$ in the surface water, from 6.78 to $66.55 \mathrm{ng} \mathrm{L}^{-1}$ dry weight in the SPM, and from 0.83 to $7.29 \mathrm{ng} \mathrm{g}^{-1}$ dry weight in the sediment. The PCB concentrations in water, SPM, and sediment were moderate relative to those reported for other estuary and marine systems around the world. Sedimentary PCB concentrations decreased offshore due to the active deposition of laterally transported river-borne particles. The predominance of the highly chlorinated congeners for the water, SPM, and sediment samples are an indication of either a lack of degradation or the presence of nearby or recent releases into the environment.
\end{abstract}

(C) 2013 Elsevier Ltd. All rights reserved.

\section{Introduction}

Polychlorinated biphenyls (PCBs) are a class of organic compounds with 1-10 chlorine atoms attached to a biphenyl molecule (Xia et al., 2012). They are extremely persistent synthetic chemicals that were once heavily used as electric insulators in transformers, hydraulic fluids, and paint additives (Waid, 1987; Zhang et al., 2011). In the 1960s and 1970s, their presence in the environment and their toxicity to humans and wildlife were recognized, leading to a 1979 federal ban on their sale and production in America (Davis et al., 2007). Despite being banned in the developed world, PCBs are still being produced and used in many developing countries (Zhou et al., 2001). These compounds may be supplied to coastal zones through rivers (Van Zoest and Van Eck, 1990), atmospheric deposition (Sanders et al., 1996), spills (Ferreira and Vale, 2000), and the dumping of dredged material (Tang and Myers, 2002). Since the 1990s, many studies have been conducted on the contamination of PCBs in estuaries on a global scale (Van Zoest and Van Eck, 1990; Ferreira et al., 2003; Zhou et al., 2001; Davis et al., 2007; Wang et al., 2011).

China began to produce PCBs in 1965 and ceased in 1974, with a total of approximately 10,000 tons of PCBs produced, including 9000 tons of tri-PCBs and 1000 tons of penta-PCBs (Xing et al., 2005). Following the ban on the production and use of PCBs, most of the outdated PCB-containing equipment (equipment containing

\footnotetext{
* Corresponding author. Tel./fax: +86 1058807172.

E-mail address: hemc@bnu.edu.cn (M. He).
}

PCB as a dielectric fluid) was removed from use and stored. However, the widespread production and use of PCBs before their legal restriction has led to serious contamination, and PCBs continue to be released from old equipment and waste sites, posing a threat to human health and the environment (Xing et al., 2005; Li et al., 2012). Several studies have already been reported on the PCB distribution in Chinese rivers, estuaries, and seas (Zhang et al., 2004, 2010, 2011). However, few studies have surveyed PCB contamination in the Liao River watershed.

The Liao River watershed, including the Liao River (Liao River) and Daliao (Hun River, Taizi River and Daliao River) water systems, flows into Liaodong Bay of the Bohai Sea. The Daliao River watershed has been subject to heavy anthropogenic influences as a result of the rapid development of the economy over the past ca. 50 years. Approximately 2074 million tons of industrial and domestic wastewater is discharged annually into the Daliao River catchment (SEPA of China, 2004). One of the most important heavy industrial complexes in Northeast Asia, including chemical/petrochemical, steel-iron, and machinery industries, is located near the Daliao River water system. The Daliao River watershed accepts approximately $60 \%$ of the pollutant discharge load of the entire Liao River watershed. Although some previous investigations focused on the PCB concentrations in the rivers of the Daliao River watershed (Wang et al., 2007), little data is available on the PCB distribution in the Daliao River estuary, despite its being a major pollution source for Liaodong Bay.

This study aims to assess the distribution and characteristics of selected parent PCBs in Daliao River estuary environments, including water, suspended particles, and sediments. 


\section{Materials and methods}

\subsection{Sampling and sample treatment}

The locations of the sampling stations are shown in Fig. 1. The sampling campaign was conducted at 39 sites during August 2007, which is part of the dry season. Sites 1-35 are located offshore of the Daliao River estuary. From site 1 to 35 , we set 6-7 sampling sections. For each section, we set 4-5 sample sites except the last sampling section (site 26-35) which is much longer than the others. These sites have freshwater inputs but are subject to several sources of contamination from anthropogenic activity. For these 35 sites, 12 water and 7 suspended particulate matter (SPM) samples and 35 sediment samples were collected. To compare the contamination by PCBs in Daliao River estuary to that in the rivers of the Daliao River watershed, four water, SPM, and sediment samples were collected per site from the Hun River (sites 36-37), the Taizi River (site 38), and the Daliao River (site 39). These four sites are not shown in Fig. 1.

Subsurface $(0.5 \mathrm{~m})$ water samples from the Daliao River estuary and Daliao River were collected from aboard a chartered vessel. Throughout the sample collection, a global positioning system

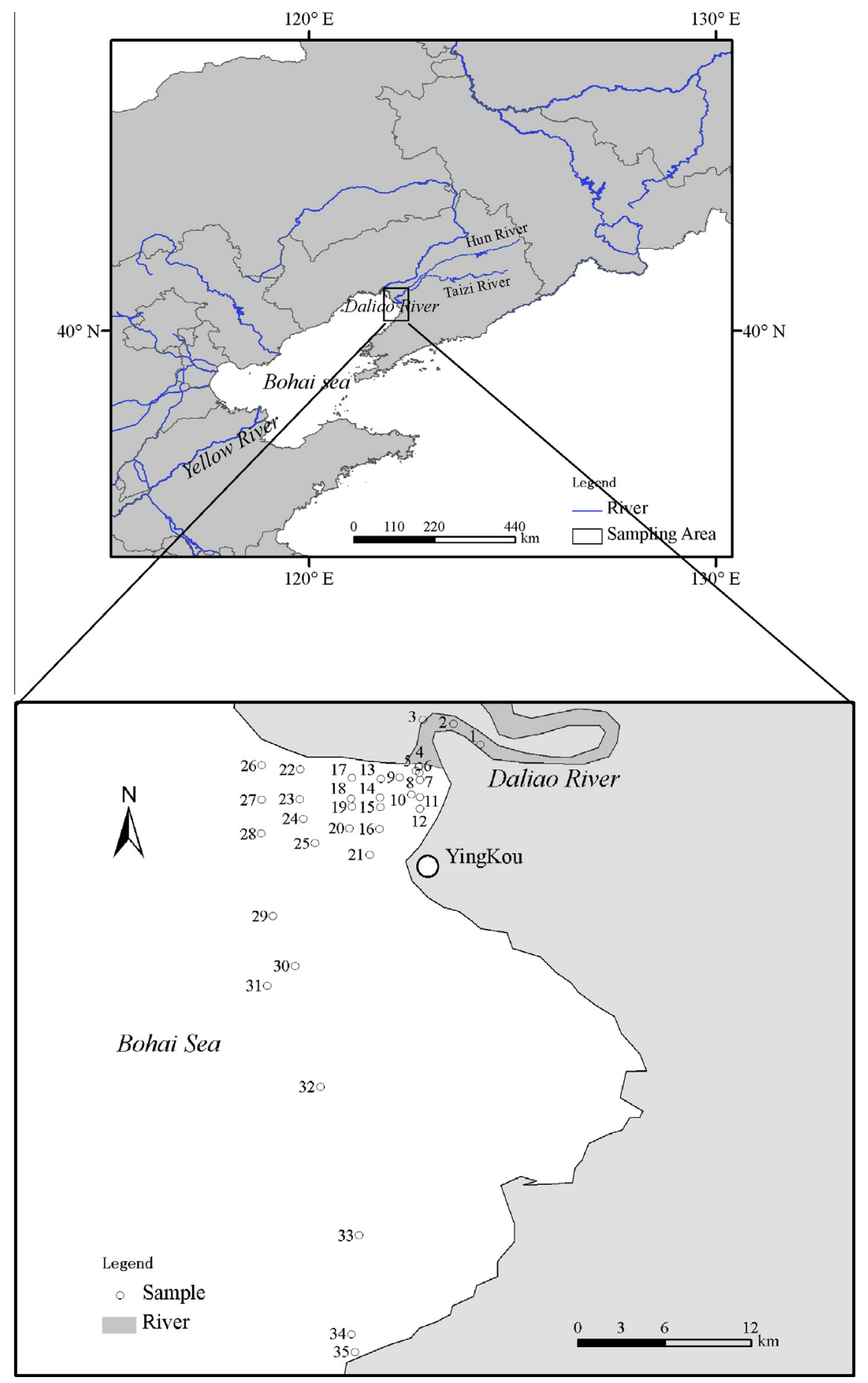

Fig. 1. Study area and sampling locations for the Daliao River and estuary, China. 
(GPS) was used to locate the sampling positions, and a conductivity/temperature/DO/pH sensor was used to obtain these master variables. Samples were collected using precleaned glass bottles. After returning to the laboratory, aliquots of the sample were filtered through polytetrafluoroethylene (PTFE) filters $(0.45 \mu \mathrm{m}$, $d=50 \mathrm{~mm}$, Millipore, USA) to yield dissolved samples and SPM for PCB analysis. The SPM samples were freeze-dried, stored in aluminum foil in desiccators until extraction and then kept in a refrigerator at $-20^{\circ} \mathrm{C}$ before analysis. The water samples were also filtered to determine the SPM concentration, with sub-samples of filtrates being acidified for dissolved organic carbon (DOC) analysis using a liquid total organic carbon analyzer.

Sediments were collected from 39 sampling sites (Fig. 1), of which 35 sites were located within the Daliao River estuary and four were located within the Daliao River watershed. Samples from the top $5 \mathrm{~cm}$ of the sediment were taken in August 2007 using a stainless-steel grab sampler and placed in pre-cleaned glass jars. The sediment samples were cooled in a refrigerator $\left(0^{\circ} \mathrm{C}\right)$ during transport to the laboratory, where they were stored at $-20^{\circ} \mathrm{C}$ until further analysis. Frozen aliquots of sediments were freeze-dried using a freeze-drier (FD-1A, China), ground with a mortar, sieved through a 100-mesh sieve, and then stored in pre-cleaned dark glass bottles before extraction.

\subsection{Chemicals and materials}

Reference PCBs were obtained from Accustandard, Inc. (New Haven, CT) (catalog numbers C-QME-01) containing the 41 following congeners: tri- $(17,18,28,31,33)$, tetra- $(44,49,52,70,74)$, penta- $(82,87,95,99,101,105,110,118)$, hexa- $(128,132,138$, $149,151,153,158,169)$, hepta- $(170,171,177,180,183,187$, $191)$, octa- $(194,195,199 / 201,205)$, nona- $(206,208)$, and deca(209). Internal Standards (IS) of pentachloronitrobenzene and surrogate of 2,4,5,6-tetrachloro-m-xylene and decachlorobiphenyl were purchased from Aldrich Co. (Aldrich Co., USA). All solvents used for sample processing and analysis (dichloromethane, methanol, ethyl acetate, hexane, and acetone) were HPLC grade from Tedia Co. (Tedia, USA). Deionized water was produced by a Milli-Q system (Millipore Co., USA)

\subsection{Sample extraction}

The water samples were extracted using a solid-phase extraction (SPE) system from Supelco following established procedures (Zhou et al., 2001). The Supelco SPE cartridges (C18) were first washed with $5 \mathrm{~mL}$ of dichloromethane and then conditioned with $5 \mathrm{~mL}$ of methanol followed by $5 \mathrm{~mL}$ of deionized water. Water samples (2 L) spiked with 2,4,5,6-tetrachloro-m-xylene and decachlorobiphenyl (in hexane) as a surrogate standard prior to extraction were passed through the cartridges at a flow rate of

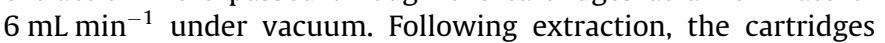
were eluted with $15 \mathrm{~mL}$ of ethyl acetate. After the water was removed from the extracts by ashed $\mathrm{Na}_{2} \mathrm{SO}_{4}$, the extracts were reduced in volume by $\mathrm{N}_{2}$ blow-down in a water bath.

The sediment samples were extracted using the National Reference Methods for Marine Pollution Monitoring Nos. HY003.5-91 (Ministry of Oceanography, 1991). First, $20 \mathrm{~g}$ of the sample was Soxhlet extracted using $200 \mathrm{~mL}$ of a hexane/acetone solvent mixture (1:1) for $24 \mathrm{~h}$. The extracts were passed through a Florisil column $(18 \mathrm{~cm})$ and eluted with $100 \mathrm{~mL}$ of hexane. The extract was concentrated to $1-2 \mathrm{~mL}$ by a rotary vacuum evaporator and further to $0.5 \mathrm{~mL}$ under a gentle stream of nitrogen gas. Pentachloronitrobenzene was added as an internal standard. PCB analysis was carried out on a gas chromatograph coupled to a mass spectrometer (GC-MS).

\subsection{Analyses}

The PCB concentrations were determined using a ThermoQuest gas chromatograph/mass spectrometer (GC/MS) (ThermoQuest, San Jose, CA, USA) with a DB- 5 column $(30 \mathrm{~m} \times 0.25 \mathrm{~mm}$ ID, film thickness $0.25 \mu \mathrm{m}$ ) (J \& W Services and Equipment Co., USA). The injection and interface temperatures were set to 290 and $250{ }^{\circ} \mathrm{C}$, respectively. The samples were injected under splitless mode, and the oven temperature was programmed as follows: $100{ }^{\circ} \mathrm{C}$ for $3 \mathrm{~min}, 6^{\circ} \mathrm{C} \mathrm{min}^{-1}$ to $290^{\circ} \mathrm{C}$ (hold for $3 \mathrm{~min}$ ). The quantification was conducted in selective ion monitoring mode (SIM). The individual PCB concentrations were obtained using the internal standard peak area method and a six-point calibration curve for individual components. All concentrations were normalized to dry sediment weight and were not surrogate recovery corrected.

\subsection{Quality assurance}

All data were subject to strict quality control procedures. For every set of samples, a procedural blank and a spiked sample with standards were used to check interferences and avoid crosscontamination. Surrogate standards were added to all samples prior to extraction to quantify procedural recoveries. The surrogate recovery standards were 2,4,5,6-tetrachloro-m-xylene and decachlorobiphenyl. Prior to extraction, samples were spiked with surrogate standards. Surrogate standards in water and sediment samples were determined with good precision. The method limit of detection (MLD) ranged from 0.01 to $0.07 \mathrm{ng} \mathrm{L}^{-1}$ for water and SPM samples and from 0.01 to $0.06 \mathrm{ng} \mathrm{g}^{-1}$ for sediment samples. The spiked recovery of PCB congeners ranged from $62.41 \pm 14.96 \%$ to $119.02 \pm 7.08 \%$ for water samples, and from $69.41 \pm 9.97 \%$ to $127.42 \pm 15.43 \%$ for sediment samples. Each extract was analyzed in duplicate, and the relative standard deviations were less than 20\%. In addition, the errors involved in sampling were assessed by carrying out triplicate sampling of water at the same site and analysis of the sample extracts. The results showed good reproducibility for the sampling process.

\subsection{Other analyses}

Sub-samples were used to determine the physicochemical properties, including the $\mathrm{pH}$ values, total organic carbon (TOC), total inorganic carbon (TIC), and SPM contents for the water samples and the TOC, black carbon (BC), and water content for sediment samples.

IBM SPSS 13.0 software was used to understand the distribution of PCB congeners in surface water, SPM, and sediment. The Pearson correlation coefficients between the levels of the total PCB congeners and relevant physicochemical parameters were determined.

\section{Results and discussion}

\subsection{PCB distribution in water, SPM, and sediment}

\subsubsection{Aqueous-phase PCBs in surface water}

The $\Sigma 41 \mathrm{PCB}$ concentrations in the aqueous phase of the Daliao River estuary samples ranged from 5.51 to $40.28 \mathrm{ng} \mathrm{L}^{-1}$, with a mean concentration of $16.91 \mathrm{ng} \mathrm{L}^{-1}$ (Table 1). PCB 128 and $138 / 158$ were the $\mathrm{PCB}$ residues most often found in the aqueous phase in surface water, whereas PCB 82, 105, and 208 were not detected in any of the samples. Fig. 2a illustrates the total concentration profiles of PCBs from 12 sampling sites. The highest levels of PCBs in the Daliao River estuary were found at site 6 , which was close to a sewage outfall and industrial discharges at the mouth of the Daliao River estuary, and reflected the potential PCB input 
Table 1

Polychlorinated biphenyl concentrations in the surface water ( $\mathrm{n} \mathrm{L} \mathrm{L}^{-1}$ ), SPM (ng L ${ }^{-1}$ ), and sediment (ng g ${ }^{-1}$ ) of the Daliao River estuary.

\begin{tabular}{|c|c|c|c|c|c|c|c|c|c|c|}
\hline \multicolumn{2}{|c|}{ PCB number } & \multicolumn{3}{|c|}{ Surface water $(n=12)$} & \multicolumn{3}{|l|}{$\operatorname{SPM}(n=7)$} & \multicolumn{3}{|c|}{ Sediment $(n=35)$} \\
\hline & & Range & Mean & SD & Range & Mean & SD & Range & Mean & SD \\
\hline \multirow[t]{3}{*}{$3 \mathrm{CB}$} & $17 / 18$ & $0-0.28$ & 0.15 & 0.09 & n.d. & n.d. & n.d. & $0-0.02$ & 0.01 & 0.01 \\
\hline & $28 / 31$ & $0-0.25$ & 0.05 & 0.08 & $0-0.28$ & 0.12 & 0.08 & $0-0.03$ & 0.01 & 0.01 \\
\hline & 33 & $0-0.33$ & 0.13 & 0.09 & $0-0.19$ & 0.08 & 0.10 & $0-0.17$ & 0.01 & 0.03 \\
\hline \multirow[t]{5}{*}{$4 \mathrm{CB}$} & 44 & $0-0.50$ & 0.09 & 0.15 & n.d. & n.d. & n.d. & $0-0.03$ & 0.01 & 0.01 \\
\hline & 49 & $0-0.25$ & 0.08 & 0.11 & $0.07-0.31$ & 0.16 & 0.09 & $0.01-0.11$ & 0.02 & 0.02 \\
\hline & 52 & $0-0.18$ & 0.02 & 0.05 & $0-0.24$ & 0.13 & 0.10 & $0-0.05$ & 0.01 & 0.01 \\
\hline & 70 & $0-0.48$ & 0.08 & 0.14 & $0-0.11$ & 0.03 & 0.05 & $0-0.01$ & 0.00 & 0.00 \\
\hline & 74 & $0-0.50$ & 0.10 & 0.15 & $0-0.40$ & 0.08 & 0.14 & $0-0.02$ & 0.01 & 0.01 \\
\hline \multirow[t]{8}{*}{$5 \mathrm{CB}$} & 82 & n.d. & n.d. & n.d. & n.d. & n.d. & n.d. & n.d. & n.d. & n.d. \\
\hline & 87 & $0-5.65$ & 1.01 & 1.53 & $0-0.91$ & 0.25 & 0.43 & $0-0.14$ & 0.05 & 0.05 \\
\hline & 95 & $0.11-6.25$ & 1.14 & 1.78 & $0.29-4.98$ & 1.19 & 1.68 & $0-0.20$ & 0.08 & 0.05 \\
\hline & 99 & $0-1.70$ & 0.59 & 0.55 & $0-3.97$ & 0.99 & 1.41 & $0-0.14$ & 0.06 & 0.04 \\
\hline & 101 & $0-1.87$ & 0.73 & 0.65 & $0-4.25$ & 0.85 & 1.57 & $0-0.16$ & 0.05 & 0.05 \\
\hline & 105 & n.d. & n.d. & n.d. & n.d. & n.d. & n.d. & n.d. & n.d. & n.d. \\
\hline & 110 & $0-1.06$ & 0.12 & 0.31 & $0-0.16$ & 0.03 & 0.06 & $0-0.68$ & 0.03 & 0.12 \\
\hline & 118 & $0-5.23$ & 0.84 & 1.75 & $0-3.34$ & 0.65 & 1.27 & $0-0.38$ & 0.08 & 0.07 \\
\hline \multirow[t]{7}{*}{$6 C B$} & 128 & $0.27-3.95$ & 0.98 & 1.00 & $0-1.60$ & 0.58 & 0.53 & $0-0.15$ & 0.06 & 0.03 \\
\hline & 132 & $0-0.33$ & 0.06 & 0.09 & $0-1.36$ & 0.31 & 0.47 & $0-0.14$ & 0.02 & 0.03 \\
\hline & $138 / 158$ & $0.15-1.86$ & 0.66 & 0.48 & $0-3.43$ & 0.91 & 1.14 & $0.03-0.29$ & 0.06 & 0.05 \\
\hline & 149 & $0-3.48$ & 0.78 & 0.96 & $0-3.98$ & 0.64 & 1.48 & $0-0.21$ & 0.04 & 0.04 \\
\hline & 151 & $0-1.60$ & 0.52 & 0.54 & $0-0.69$ & 0.39 & 0.25 & $0-0.13$ & 0.04 & 0.03 \\
\hline & 153 & $0-1.40$ & 0.50 & 0.57 & $0-2.02$ & 1.90 & 0.49 & $0-0.16$ & 0.05 & 0.05 \\
\hline & 169 & $0-6.14$ & 1.52 & 1.69 & $0.56-15.28$ & 3.91 & 5.16 & $0.07-5.07$ & 0.37 & 0.86 \\
\hline \multirow[t]{7}{*}{$7 \mathrm{CB}$} & 170 & $0-2.29$ & 0.57 & 0.66 & $0-7.72$ & 1.28 & 2.85 & $0-0.16$ & 0.04 & 0.04 \\
\hline & 171 & $0-1.32$ & 0.53 & 0.39 & $0-1.98$ & 0.61 & 0.65 & $0-0.14$ & 0.04 & 0.03 \\
\hline & 177 & $0-1.09$ & 0.41 & 0.35 & $0-2.66$ & 0.63 & 0.91 & $0-0.11$ & 0.04 & 0.03 \\
\hline & 180 & $0-0.64$ & 0.27 & 0.24 & $0-2.08$ & 0.42 & 0.75 & $0-0.12$ & 0.03 & 0.02 \\
\hline & 183 & $0-0.99$ & 0.51 & 0.34 & $0-1.17$ & 0.31 & 0.45 & $0-0.11$ & 0.03 & 0.03 \\
\hline & 187 & $0-0.84$ & 0.43 & 0.27 & $0-0.94$ & 0.31 & 0.35 & $0-0.13$ & 0.04 & 0.03 \\
\hline & 191 & $0-1.48$ & 0.59 & 0.37 & $0-2.70$ & 0.80 & 0.88 & $0-0.10$ & 0.03 & 0.03 \\
\hline \multirow[t]{4}{*}{$8 \mathrm{CB}$} & 194 & $0-1.14$ & 0.51 & 0.41 & $0-1.39$ & 0.53 & 0.49 & $0-2.83$ & 0.17 & 0.48 \\
\hline & 195 & $0-3.02$ & 0.48 & 0.87 & n.d. & n.d. & n.d. & $0-0.16$ & 0.03 & 0.05 \\
\hline & 199 & $0-3.43$ & 0.54 & 0.95 & $0-0.85$ & 0.46 & 0.35 & $0-0.13$ & 0.02 & 0.04 \\
\hline & 205 & $0-1.02$ & 0.48 & 0.39 & $0-2.10$ & 0.81 & 0.72 & $0-0.19$ & 0.07 & 0.05 \\
\hline \multirow[t]{2}{*}{$9 \mathrm{CB}$} & 206 & $0-6.04$ & 0.81 & 1.69 & $0-6.80$ & 1.40 & 2.46 & $0-0.31$ & 0.09 & 0.09 \\
\hline & 208 & n.d. & n.d. & n.d. & $0-0.40$ & 0.11 & 0.19 & $0-0.20$ & 0.03 & 0.05 \\
\hline $10 \mathrm{CB}$ & 209 & $0-2.91$ & 0.66 & 0.85 & $0-1.17$ & 0.93 & 1.35 & $0-0.25$ & 0.08 & 0.06 \\
\hline \multicolumn{2}{|l|}{$\Sigma \mathrm{PCB}$} & $5.51-40.28$ & 16.91 & 11.65 & $6.78-66.55$ & 21.81 & 21.29 & $0.83-7.29$ & 1.77 & 1.21 \\
\hline
\end{tabular}

n.d.: not determined.
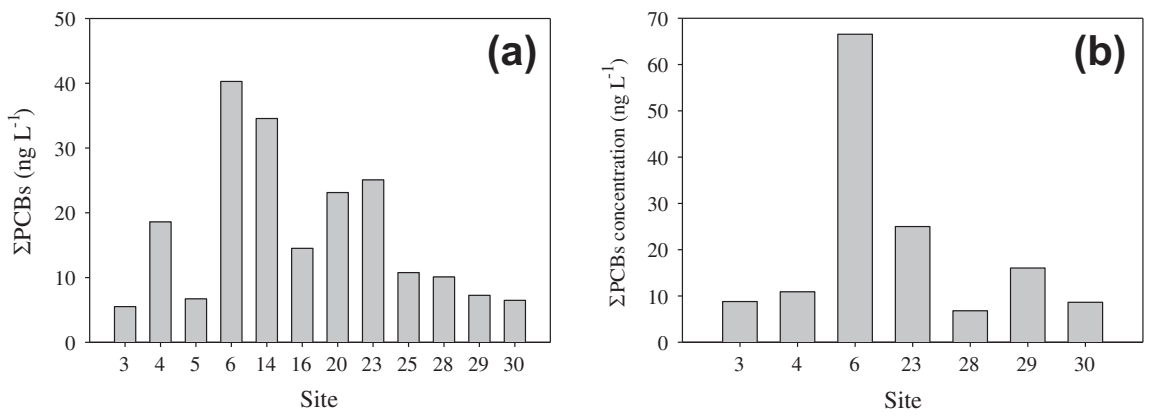

Fig. 2. Comparison of PCB concentrations in surface water (a) and SPM (b) in the Daliao River estuary.

from sewage discharges. High concentrations were also found at sites 20 and 23. These two sites were close to the estuarine shores; the high concentrations found at the two sites might be associated with the accumulation of urban runoff, sewage discharge, and wastewater from industrial area discharges. In addition, many boats and ships travel in this area, constituting many non-point sources and contributing to the high concentrations of PCBs detected. The concentration of PCBs in the Daliao River was higher than that of the Daliao River estuary, whereas that of sites 36 and 37 in the Hun River were 35.73 and $24.08 \mathrm{ng} \mathrm{L}^{-1}$, respectively; that of site 38 in the Taizi River was $16.85 \mathrm{ng} \mathrm{L}^{-1}$; and that of site 39 in the Daliao River was $53.87 \mathrm{ng} \mathrm{L}^{-1}$. The results suggest that the pollutants in the aqueous phase were diluted as they were discharged from the river to the ocean through the estuary.

In comparison with those reported for other estuary and marine systems around the world, the PCB concentrations in the Daliao River estuary were moderate. The level of $\Sigma$ PCBs in the Daliao River estuary (5.51-40.28 $\mathrm{ng} \mathrm{L}^{-1}$ ) was lower than that in Daya 


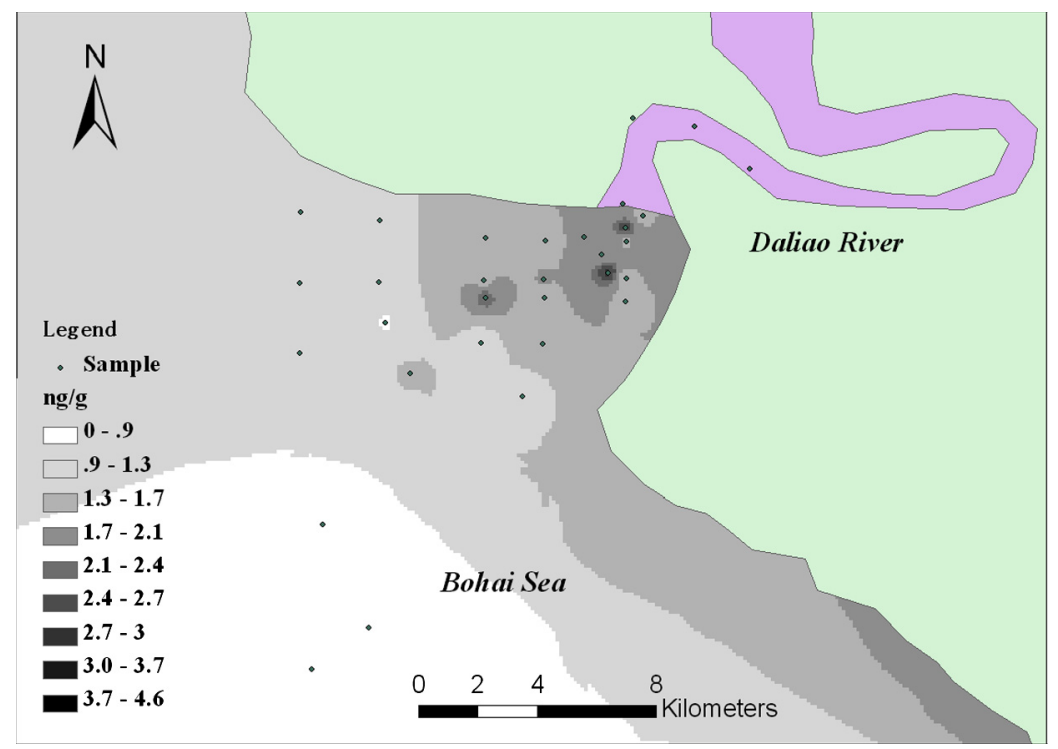

Fig. 3. PCB concentration in the sediment of the Daliao River estuary.
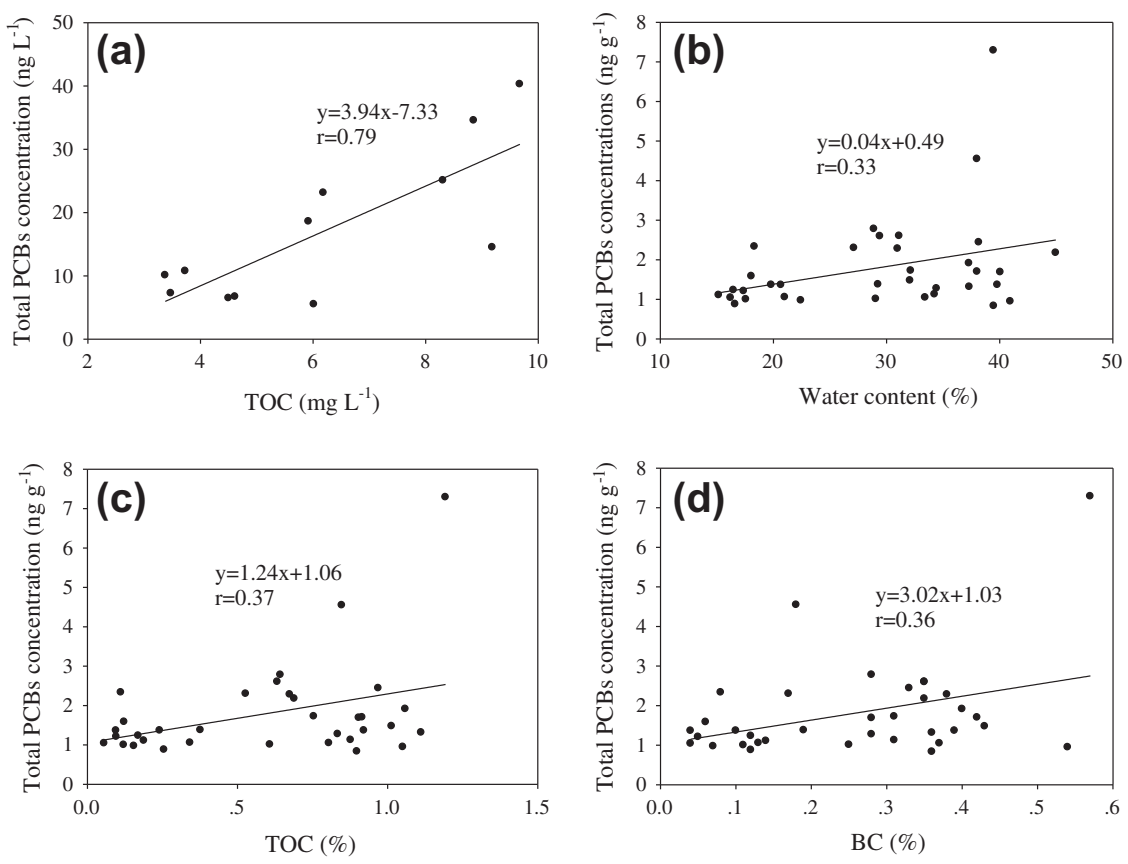

Fig. 4. Relationship between the total PCB concentration and physicochemical parameters in surface water (a) and sediment (b, c, and d) in the Daliao River estuary.

Bay (91.1-1355.3 $\mathrm{ng} \mathrm{L}^{-1}$ ) in China (Zhou et al., 2001) and Midway Atoll (9.1-63.0 $\mathrm{ng} \mathrm{L}^{-1}$ ) in the North Pacific Ocean (Hope et al., 1997) but much higher than that reported in Xiamen Harbor (0.1-1.7 $\mathrm{ng} \mathrm{L}^{-1}$ ) in China (Zhou et al., 2000) and in the Humber estuary (approximately $1 \mathrm{ng} \mathrm{L}^{-1}$ ) in England (Zhou et al., 1996).

\subsubsection{PCBs in SPM}

The concentrations of PCB congeners in the SPM of the Daliao River estuary are presented in Table 1 . The individual congener distributions of PCB, PCB17/18, 44, 82, 105, and 195 were not detected for all SPM samples. The total PCB concentration ranged from 6.78 to $66.55 \mathrm{ng} \mathrm{L}^{-1}$, with an average concentration of $21.81 \mathrm{ng} \mathrm{L}^{-1}$, whereas that of sites 36 and 37 in the Hun River were 40.11 and $39.09 \mathrm{ng} \mathrm{L}^{-1}$, respectively; that of site 38 in the Taizi River was $56.84 \mathrm{ng} \mathrm{L}^{-1}$; and that of site 39 in the Daliao River was
$76.96 \mathrm{ng} \mathrm{L}^{-1}$. The PCB level in the Daliao River estuary was similar to that in Daliao River, unlike the case of the aqueous phase, because of the adsorption of PCBs on SPM and the different SPM contents. Fig. $2 \mathrm{~b}$ shows that the most highly contaminated locations of the Daliao River estuary were sites $6\left(66.55 \mathrm{ng} \mathrm{L}^{-1}\right)$ and 23 (24.99 $\mathrm{ng} \mathrm{L}^{-1}$ ). The high concentrations found at these sites might be associated with the input from the Daliao River and subsequent adsorption onto the SPM.

To understand the status of PCB-related contaminants in the studied area, the variations of the PCB concentration were compared with similar results from various published reports conducted at different sites worldwide. The $\Sigma$ PCB level in the Daliao River estuary (6.78-66.55 $\left.\mathrm{ng} \mathrm{L}^{-1}\right)$ was higher than that in the Portuguese coast (4.2-30.1 $\mathrm{ng} \mathrm{L}^{-1}$ ) (Ferreia et al., 2003) but much lower than that reported in the Newark Bay estuary 

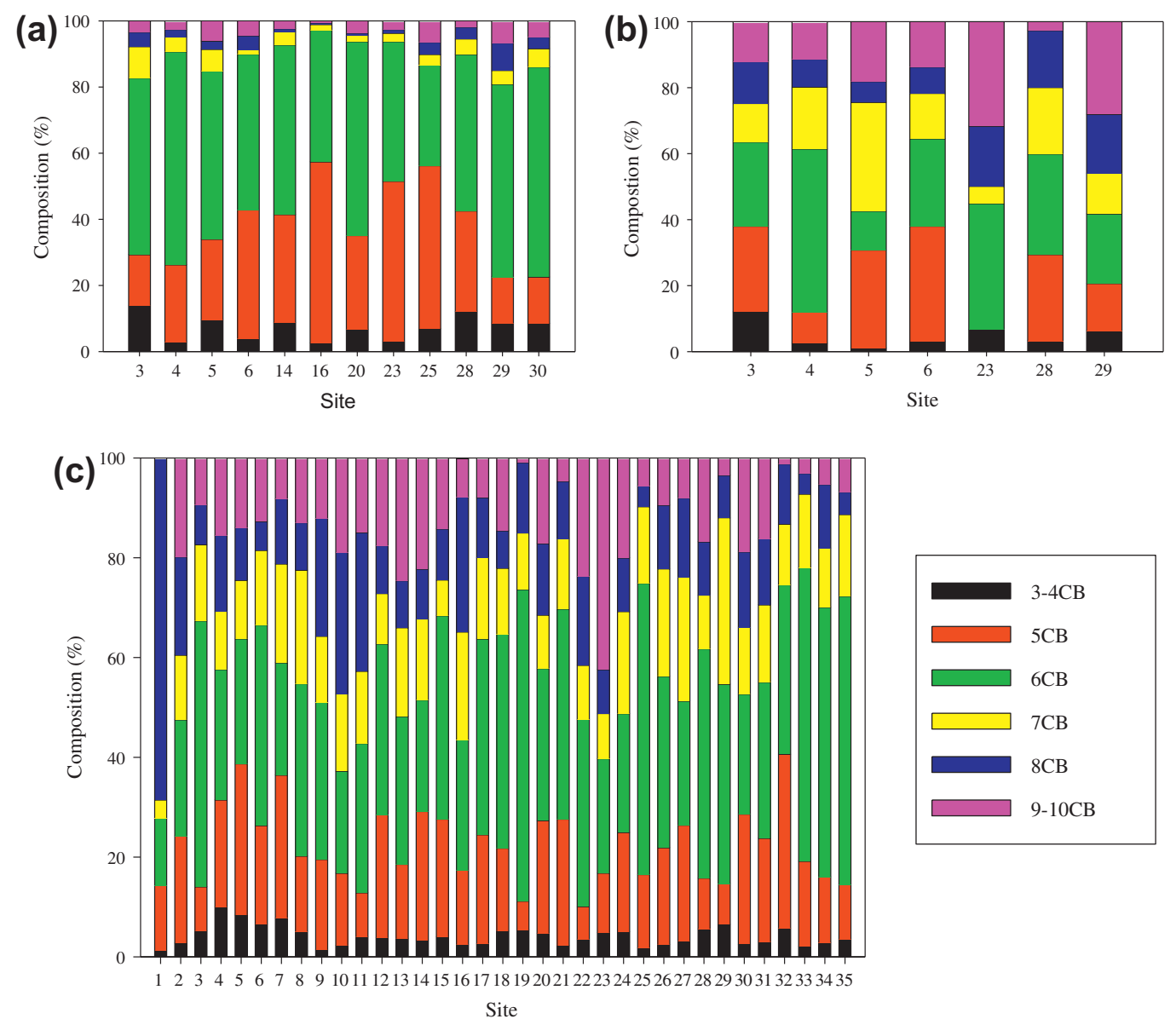

Fig. 5. Percentage composition of polychlorinated biphenyls in the surface water (a), SPM (b), and sediment (c).

(466-966 ng L ${ }^{-1}$ ) (Dimou et al., 2004). The concentrations of PCBs were fairly low in the Daliao River estuary relative to those reported in other estuary and marine systems around the world.

\subsubsection{PCBs in sediments}

The total PCB concentrations in the sediment of the Daliao River estuary ranged from 0.83 to $7.29 \mathrm{ng} \mathrm{g}^{-1}$, with a mean of $1.77 \mathrm{ng} \mathrm{g}^{-1}$ (Table 1), whereas that of the four river samples ranged from 1.65 to $15.2 \mathrm{ng} \mathrm{g}^{-1}$, with the highest level being found at site 39 in the Daliao River. In terms of individual PCB congeners, PCB 49, 138/158, and 169 were the PCB residues most often found in sediment samples, while PCB 82 and 105 were not detected in any of the samples. The PCB concentration in the sediment samples of the Taizi River and Daliao River mainstreams collected in June 2006 ranged from $1.88 \mathrm{ng} \mathrm{g}^{-1}$ to $16.88 \mathrm{ng} \mathrm{g}^{-1}$ (Wang et al., 2007). In the Daliao River estuary, the highest concentration was found at site 3 , which is located in the mouth of the Daliao River estuary close to a sewage outfall and industrial discharges. Heavy concentrations were also found at sites $1\left(4.54 \mathrm{ng} \mathrm{g}^{-1}\right), 7\left(2.60 \mathrm{ng} \mathrm{g}^{-1}\right)$, and $10\left(2.78 \mathrm{ng} \mathrm{g}^{-1}\right)$, which are located at the mouth of the Daliao River estuary, reflecting a recent deposition and accumulation of PCBs. For site 6, a low level of PCBs was found in sediment compared to a high PCB concentration in water and SPM, which can be attributed to recent PCB input near the area. The input of PCBs from the Daliao River may be the main pollution maker. In the Daliao River estuary, PCB concentrations decreased offshore (Fig. 3), indicating that the PCBs in water were deposited when water flowed through the mouth of the Daliao River estuary.
The concentrations of total PCBs in the Daliao River estuary were higher than those in Jiulong estuary, China $\left(<0.01-0.32 \mathrm{ng} \mathrm{g}^{-1}\right)$ (Zhou et al., 2000) and Saigon-Dong Nai estuary, Vietnam (0.49$1.2 \mathrm{ng} \mathrm{g}^{-1}$ ) (Minh et al., 2007) but lower than those recorded at several other sites in China: Daya Bay (0.85-27.37 $\mathrm{ng} \mathrm{g}^{-1}$ ) (Zhou et al., 2001), Liaohe River (1.853-1075.606 $\mathrm{ng} \mathrm{g}^{-1}$ ) (Zhang et al., 2010), and the New Territories in Hong Kong (43-461 $\mathrm{ng} \mathrm{g}^{-1}$ ) (Zhou et al., 1999). The PCB concentrations in the Daliao River estuary are moderate relative to those reported in other estuaries around the world.

\subsection{Correlation of PCBs with physicochemical parameters}

PCBs are hydrophobic, prefer to associate with colloids, dissolved organic matter, and SPM in water, and ultimately deposit in the sediment. Many studies have proven that the concentrations of PCBs in sediment are influenced by dissolved organic carbon (Lee et al., 2001; Jeong et al., 2001). As shown in Fig. 4, significant positive correlations were found between PCBs and TOC $\left(r_{\mathrm{TOC}}=0.79, n=12, P<0.01\right)$ in water samples from the Daliao River estuary, whereas no correlation was found between PCBs and $\mathrm{pH}$ $\left(r_{\mathrm{pH}}=0.10, n=12, P>0.05\right)$. In this study, the relationship between the concentrations of PCBs and other physicochemical parameters of the sediment samples has also been analyzed. The results show that there is no correlation between total PCB concentration and TOC or BC in the sediment $\left(r_{\text {water }}\right.$ content $=0.33, P<0.001$; $\left.r_{\mathrm{TOC}}=0.37, P=0.016 ; r_{\mathrm{BC}}=0.36, P=0.005 ; n=35\right)$. Studies by Gschwend and $\mathrm{Wu}(1985)$ and Zhou et al. (2007) suggested that natural colloidal matter has a non-negligible solubility enhancement effect 
on the distribution of hydrophobic organic contaminants between aqueous and sediment-bound phases. This effect makes a compound appear to be more soluble in water and reduces the total sediment-sorbed amount (Gao et al., 1997). Second, the partitioning of PCBs into TOC or BC in the Daliao River estuary may not have reached equilibrium, resulting in low correlations between PCBs and TOC or BC in sediments.

\subsection{PCB composition and source identification}

Fig. 5 shows the PCB composition patterns in the water, SPM, and sediment samples. For water samples, the PCBs are dominated by penta- and hexa-PCBs. The distribution profiles in the sediment were very similar to those in SPM and showed a marked predominance of the highly chlorinated congeners, including penta-, hexa, hepta-, and octa-PCBs. Pentachlorinated biphenyl is the main PCB present in paint, and the total pentachlorinated biphenyl contents are highest in the water and SPM samples of the Daliao River estuary (Dai et al., 2011). This finding suggests that paint from ships' bottoms is responsible for the PCB residue in the estuary. For sediment samples, the third panel shows quite a regular pattern in the PCB composition of sediment samples in sites 2 to 35. However, site 1 concentrations happen to be largely dominated by $8 \mathrm{CBs}$. Evidence suggests that more highly chlorinated $\mathrm{PCB}$ congeners commonly accumulate near the source of PCBs (Ashley and Baker, 1999; de Mora et al., 2005; Hong et al., 2005), whereas less chlorinated PCB congeners may be transported over longer distances (Muir et al., 1996). This may be a possible explanation to the problem.

The tendency of the congener distribution to be dominated by more highly chlorinated compounds is consistent with that of sediments from the Pearl River Delta in South China, suggesting the basic trend of PCBs in coastal sediment: a decrease in the relative abundance of less chlorinated congeners with a parallel increase of more highly chlorinated PCBs (Wang et al., 2011). A previous study showed that PCBs tend to become slowly dechlorinated due to degradation. The samples that still contain highly chlorinated congeners are an indication of the absence of degradation or the presence of nearby or recent releases into the environment (Spongberg, 2004)

\subsection{Ecotoxicological concerns}

PCBs are toxic to aquatic organisms. To evaluate the ecotoxicological aspect of PCB contamination, some published quality guidelines were applied in this study. According to the relevant USEPA guideline, the concentration of PCBs should be less than $14 \mathrm{ng} \mathrm{L}^{-1}$ for water, which is considered to be safe for aquatic and human health (Zhang et al., 2004). Based on this guideline, the surface water of Daliao River estuary is heavily polluted by PCBs (5.51$40.28 \mathrm{ng} \mathrm{L}^{-1}$ ), which could have adverse effects on the aquatic environment and human health. The effects range low (ERL) and the effects range median (ERM) have been used for the assessment of aquatic sediments with low-to-high impact values (Long et al., 1995). The ERL (22.7 $\mathrm{ng} \mathrm{g}^{-1}$ dry weight) suggests that PCBs can exert toxic biological effects on aquatic organisms, while the ERM (180 $\mathrm{ng} \mathrm{g}^{-1}$ dry weight) indicates the strong possibility of PCBs posing detrimental biological effects on aquatic organisms (Long et al., 1995). In this study, no samples were found to contain $\Sigma$ PCB concentrations exceeding the ERL value $\left(22.7 \mathrm{ng} \mathrm{g}^{-1}\right)$, indicating that the $\mathrm{PCB}$ concentration in sediments from the Daliao River estuary have low biological effects on aquatic organisms. Therefore, comparing the PCB concentrations in water and sediment with the quality guidelines, negative toxic effects could exist for the Daliao River estuary, although they may not be significant.

\section{Conclusion}

This study has provided important data on parent PCB levels in the water, SPM, and sediment of the Daliao River estuary, which is located in a heavy industrial area in northeastern China. Generally, the PCB concentrations in the Daliao River estuary were moderate in comparison with those of other estuaries and bays. No correlation was found between PCB concentrations and TOC or BC in sediment from the Daliao River estuary, but significant positive correlations were found between PCBs and TOC in water samples. The PCB composition in the water samples was comprised mainly of penta- and hexa-PCBs. The distribution profiles in sediment were very similar to those in SPM and showed a marked predominance of the highly chlorinated congeners, including penta-, hexa-, hepta-, and octa-PCBs.

\section{Acknowledgments}

The study was supported by the National Science Foundation for Innovative Research Group (No. 51121003), the Major Science and Technology Program for Water Pollution Control and Treatment (2012ZX07202002), and the Natural Science Foundation of China (No. 41201498).

\section{References}

Ashley, J.T.F., Baker, J.E., 1999. Hydrophobic organic contaminations in surficial sediments of Baltimore Harbor: inventories and sources. Environmental Toxicology and Chemistry 18, 838-849.

Dai, G.H., Liu, X.H., Liang G., Han, X, Shi, L, Cheng D.M., Gong W.W., 2011. Distribution of organochlorine pesticides (OCPs) and polychlorinated biphenyls (PCBs) in surface water and sediments from Baiyangdian Lake in North China. Journal of Environmental Sciences 23 (10), 1640-1649.

Davis, J.A., Hetzel, F., Oram, J.J., McKee, L.J., 2007. Polychlorinated biphenyls (PCBs) in an Francisco Bay. Environmental Research 105, 67-86.

de Mora, S., Fowler, S.W., Tolosa, I., Villeneuve, J.P., Cattini, C., 2005. Chlorinated hydrocarbons in marine biota and coastal sediments from the Gulf and Gulf of Oman. Marine Pollution Bulletin 50, 835-849.

Dimou, K.N., Su, T.L., Hires, R.I., 2004. Distribution of polychlorinated biphenyls in the Newark Bay Estuary. Journal of Hazardous Materials 136, 103-110.

Ferreira, A.M., Vale, C., 2000. Aumento dos níveis de PCB nas partículas em suspensão, peixes e moluscos do estuário do Tejo e zona costeira adjacente após um derrame acidental. In: Duarte, A., Vale, C., Prego, R. (Eds.), Estudos de Biogeoquímica na Zona Costeira Ibérica. Universidade de Aveiro, Portugal, pp. 55-60.

Ferreira, A.M., Martins, M., Vale, C., 2003. Influence of diffuse sources on levels and distribution of polychlorinated biphenyls in the Guadiana River estuary, Portugal. Marine Chemistry 83, 175-184.

Gao, J.P., Maguhn, J., Spitzauer, P., Kettrup, A., 1997. Distribution of pesticides in the sediment of the small Teufelsweiher pond (Southern Germany). Water Research 31 (11), 2811-2819.

Gschwend, P.W., Wu, S., 1985. On the constancy of sediment-water partition coefficients of hydrophobic organic pollutants. Environmental Science and Technology 19 (1), 90-96.

Hong, S.H., Yim, U.H., Shim, W.J., Oh, J.R., 2005. Congener-specific survey for polychlorinated biphenlys in sediments of industrialized bays in Korea: Regional characteristics and pollution sources. Environmental Science and Technology 39, 7380-7388.

Hope, B., Scatolini, S., Titus, E., Cotter, J., 1997. Distribution patterns of polychlorinated biphenyl congeners in water, sediment and biota from Midway Atoll (North Pacific Ocean). Marine Pollution Bulletin 34, 548-563.

Jeong, G.H., Kim, H. Joo, Y., Kim, Y.B., So, H.Y., 2001. Distribution characteristics of PCBs in the sediments of the lower Nakdong River, Korea. Chemosphere 44, 1403-1411.

Lee, K.T., Tanabe, S., Koh, C.H. 2001. Distribution of organochlorine pesticides in sediments from Kyeonggi Bay and nearby areas, Korea. Environmental Pollution $114,207-213$

Li, W.H., Tian, Y.Z., Shi, G.L., Guo, C.S., Feng, Y.C., Yue, X.P., 2012. Source and risk assessment of PCBs in sediments of Fenhe reservoir and watershed, China. Journal of Environmental Monitoring 14, 1256-1263.

Long, E.R., MacDonald, D.D., Smith, S.L., Calder, F.D., 1995. Incidence of adverse biological effects within ranges of chemical concentrations in marine and estuary sediments. Environmental Management 19, 81-97.

Minh, N.H., Minh, T.B., Iwata, H., 2007. Persistent organic pollutants in sediments from Sai Gon-Dong Nai River Basin, Vietnam: levels and temporal trends. Archives of Environmental Contamination and Toxicology 52, 458-465.

Muir, D.C.G., Omelchenko, A., Grift, N.P., Savoie, D.A., Lockhart, W.L., Wilkinson, P., Brunskill, G.J., 1996. Spatial trends and historical deposition of polychlorinated 
biphenyls in Canadian midlatitude and Arctic lake sediments. Environmental Science and Technology 30, 3609-3617.

Sanders, G., Hamilton-Taylor, J., Jones, K.C., 1996. PCB and PAH dynamics in a small rural lake. Environmental Science and Technology 30, 2958-2966.

SEPA of China, 2004. Tenth-Five-Year Plan of Water Pollution Prevention and Control for "Three Rivers and Three Lakes", first ed. Chemical Industry Publishing Company, Beijing.

Spongberg, A.L., 2004. PCB contamination in surface sediments in the coastal waters of Costa Rica. Revista de Biologia Tropical 52, 1-10.

Tang, N.H., Myers, T.E., 2002. PCB removal from contaminated dredge material. Chemosphere 46, 477-484.

Van Zoest, R. Van Eck, G.T.M., 1990. Behaviour of particulate polychlorinated biphenyls and polycyclic aromatic hydrocarbons in the Sheldt estuary. Netherland Journal of Sea Research 26, 89-96.

Waid, J.S. (Ed.), 1987. PCBs and the Environment. CRC Press Inc., Boca Raton, FL.

Wang, H.S., Du, J., Leung, H.M., Leung, A.O.W., Liang, P., Giesy, J.P., Wong, C.K.C., Wong, M.H., 2011. Distribution and source apportionments of polychlorinated biphenyls (PCBs) in mariculture sediments from the Pearl River Delta, South China. Marine Pollution Bulletin 63, 516-522.

Wang, H.Z., He, M.C., Lin, C.Y., Quan, X.C., Guo, W., Yang, Z.F., 2007. Monitoring and assessment of persistent organochlorine residues in sediments from the Daliaohe River Watershed, Northeast of China. Environmental Monitoring and Assessment 133, 231-242.

Xia, C.H., Lam, J.C.W., Wu, X.G., Xie, Z.Q., Lam, P.K.S., 2012. Polychlorinated biphenyls (PCBs) in marine fishes from China: levels, distribution and risk assessment. Chemosphere 89, 944-949.

Xing, Y., Lu, Y.L., Dawson, R.W., Shi, Y.J., Zhang, H., Wang, T.Y., Liu, W.B., Ren, H.C., 2005. A spatial temporal assessment of pollution from PCBs in China. Chemosphere 60, 731-739.
Zhang, H.B., Li, X.H., Luo, Y.M., Li, Q.B., 2011. Depth distribution of polychlorinated biphenyls in soils of the Yangtze River Delta region, China. Geoderma 160, 408413.

Zhang, H.J., Zhao, X.F., Ni, Y.W., Lu, X.B., Chen, J.P., Su, F., Zhao, L., Zhang, N., Zhang X.P., 2010. PCDD/Fs and PCBs in sediments of the Liaohe River, China: levels, distribution, and possible sources. Chemosphere 79, 754-762.

Zhang, Z.L., Huang, J., Yu, G., Hong, H.S., 2004. Occurrence of PAHs, PCBs and organochlorine pesticides in the Tonghui River of Beijing, China. Environmental Pollution 130, 249-261.

Zhou, H.Y., Cheung, R.Y.H., Wong, M.H., 1999. Residues of Organochlorines in Sediments and Tilapia Collected from Inland Water Systems of Hong Kong. Archives of Environmental Contamination and Toxicology 36, 424431.

Zhou, J.L., Fileman, T.W., Evans, S., Donkin, P., Mantoura, R.C., Rowland, S.J., 1996 Seasonal distribution of dissolved pesticides and polynuclear aromatic hydrocarbons in the Humber Estuary and Humber coastal zone. Marine Pollution Bulletin 32, 8-9.

Zhou, J.L., Hong, H., Zhang, Z., Maskaoui, K., Chen, W., 2000. Multi-phase distribution of organic micropollutants in Xiamen Harbour, China. Water Research 34 $2132-2150$.

Zhou, J.L., Liu, R., Wilding, A., Hibberd, A., 2007. Sorption of selected endocrine disrupting chemicals to different aquatic colloids. Environmental Science and Technology 41 (1), 206-213.

Zhou, J.L., Maskaoui, K., Qiu, Y.W., Hong, H.S., Wang, Z.D., 2001. Polychlorinated biphenyls congeners and organochlorine insecticides in the water column and sediments of Daya Bay, China. Environmental Pollution 113, 373-384. 